\title{
Music therapy for human spaceflights: psycho- physiological responses of musical stimulus under hypergravity stressors
}

\author{
Luque Álvarez ${ }^{1}$, Luis \\ Széchenyi István University, \\ Faculty of Art, \\ Győr, Hungary \\ luisluquewp@gmail.com
}

\author{
Tamás Nagy ${ }^{2}$ \\ , Eötvös Loránd University, \\ Doctoral School of Linguistics, \\ Budapest, Hungary \\ nt.nagytamas@gmail.com
}

\begin{abstract}
Music has been historically reported in spaceflights as inducing on astronauts positive psychological and physiological effects in a similar manner to Guided Imagery, a technique often used by professionals in multiple settings such as sports, to reduce stress and anxiety, and improve focus prior to or during an activity, Listening to music has also been reported by trained spaceflight crews during their pressurization checks of the vehicle prior to launch. Once launched they encounter hypergravity conditions that put physiological and psychological stress upon the body, however, it is not documented the effect of this practice of listening to music acts to reduces stress. With commercial spaceflight tourism on the horizon, where a wider population will be exposed to these larger hypergravity stresses for longer periods of time, the potential for non-invasive countermeasures to reduce possible stress would be advantageous. The aim of this study was to understand if music could be used during hypergravity stress to induce a positive psychological state and reduce markers of physiological stress. The experiment was kindly supported by the European Space Agency (ESA) Education Office and the German Aerospace Center (DLR) as part of the ESA Spin your Thesis - Human Edition 2018.
\end{abstract}

\section{Keywords—human spaceflight; music therapy; hypergravity}

\section{INTRODUCTION AND METHODS}

According to the established experiment's protocol on the Short Arm Human Centrifuge (SAHC) at DLR, we based on the principles of The Bonny Method (GIM) used in Guided Imagery using music selection as a stimulus instead of an image. Music was devised for use during a controlled hypergravity environment of $1 \mathrm{Gz}$ and $1.5 \mathrm{Gz}$. Questionnaires were applied on the selection aiming to approach the subject's musical and psycho-cultural profile. 11 subjects volunteered for the study and were split into two groups according to their music styles affinity (with music $[\mathrm{n}=6]$ and without music $[\mathrm{n}=5]$. Psychological POMS tests and physiological markers including muscles tone (MyoTone Pro), galvanic skin resistance and stress hormones cortisol/cortisone measurements were performed before, during, after each centrifuge and compared between groups. According to the music period, harmonic, rhythmical character/ density and subjects preferences, two music samples were selected, edited and played separately on each centrifuge for 5 minutes. The first music sample a documentary soundtrack and the second music sample a slow movement (adagio molto e cantabile) from a classical symphony, both samples written in the key of B flat major containing harmonic modulation sequences from the classical, romantic and xx. century musical periods, including strings acoustic instrumentation in the classic orchestral formation and electronic instruments/effects.

\begin{tabular}{|c|c|c|c|c|c|c|c|}
\hline \multirow[t]{2}{*}{ Muscles } & Pre & After $1 G$ & $\begin{array}{l}\text { After } \\
1.5 \mathrm{G}\end{array}$ & Pre & After $1 G$ & $\begin{array}{c}\text { After } \\
1.5 \mathrm{G}\end{array}$ & \multirow{3}{*}{$\begin{array}{l}\text { Figure 1: Comparison of muscle properties in the control group } \\
\text { ( } \mathrm{n}=5 \text {; without music) to the music group ( } \mathrm{n}=6 ; \text { in green). } \\
\text { Oscillation Frequency (in Hertz), before (Pre) after } 1 \mathrm{G} \text { and after } \\
1.5 \mathrm{G} \text { Mean }+/- \text { SEM, each value is the mean of left and right } \\
\text { sides per subject. Significant } \mathrm{P} \text { value when } * \mathrm{p}<0.05 \text {. }\end{array}$} \\
\hline & \multicolumn{3}{|c|}{ Control group without music } & \multicolumn{3}{|c|}{ Music group } & \\
\hline $\begin{array}{l}\text { Biceps } \\
\text { Brachii } \\
\text { Long }\end{array}$ & 14.67 & 15.52 & 15.18 & 13.54 & 14.28 & 14.125 & \\
\hline Masseter & $14.9 \pm 1.06$ & $\begin{array}{c}15.44 \pm \\
1.07\end{array}$ & $\begin{array}{c}15.83 \pm \\
1.30 \\
(\mathrm{p}=0.13 \\
\text { NS) }\end{array}$ & $14.31 \pm 1.48$ & $\begin{array}{c}14.19 \pm \\
0.74\end{array}$ & $\begin{array}{c}14.26 \pm \\
0.83\end{array}$ & $\begin{array}{l}\text { Psychological POMS (profile of mood states) tests and music } \\
\text { pleasantness questionnaires results in the Music group }\end{array}$ \\
\hline $\begin{array}{l}\text { Rectus } \\
\text { Femoris }\end{array}$ & $15.62+0.86$ & $\begin{array}{c}16.2 \pm 0.66 \\
(\mathrm{p}=0.07)\end{array}$ & 16.01 & 15.35 & $\begin{array}{c}\begin{array}{c}15.78^{*}(1 \mathrm{G} \\
\text { vs Pre, } \\
\mathrm{p}<0.05)\end{array} \\
\end{array}$ & 15.89 & $\begin{array}{l}\text { participants showed a pleasantness tendency to prefer slower } \\
\text { rhythmic and lower rhythmical density music such as the slow } \\
\text { classical symphony movement. After the two centrifuges, music }\end{array}$ \\
\hline \begin{tabular}{|l} 
Rectus \\
Abdominis
\end{tabular} & 14.69 & 14.94 & 15.11 & 12.43 & 13.26 & 12.84 & pleasantness questionnaire revealed that $2 / 5$ preferred $t$ \\
\hline $\begin{array}{l}\text { Sternocleid } \\
\text { omastoid }\end{array}$ & 13.7 & 12.53 & 12.54 & 13.26 & 12.5 & 12.53 & 6 \\
\hline $\begin{array}{l}\text { Tibialis } \\
\text { Anterior }\end{array}$ & 22.97 & 21.05 & 21.31 & 22.37 & 19.1 & 19.05 & \\
\hline
\end{tabular}


documentary soundtrack and 4/5 preferred the classical slow movement. One of the subjects has remarked to strongly unlike the slow classical's composer on the pre-centrifuge questionnaires, curiously, the subject has found pleasant both samples after the centrifuge. The music group has decreased psychological tension levels from " 43 " points before the spin to " 18 " points after the spin marking a decrease of 25 points in comparison with the control group with " 33 " points before the spin and " 23 " after the spin marking a decrease of 10 points. Only the control group without music have included a subject who has increased psychological tension after the two centrifuges. Muscle tone (Myoton pro) results in music group have sown especially in the masseter muscle a tendency to decrease after the musical intervention. The masseter was physically the closest measured muscle to the music stimuli. According to the other two participating teams protocol, after each music sample, the subjects performed 5 minutes of squats exercises that may have influenced the results. Subjects that experienced hypergravity with music were less stressful or a least without significant differences in tension points and showed a tendency to decrease the stress. Galvanic skin resistance and hormonal tests are currently under treatment due to their complexity and data amount.

\section{CONCLUSIONS}

Hypergravity and music have affected all the psychological and physiological parameters. Music has decreased the stress feeling in this extreme environment, however, further experiments could provide significant outcomes statistically. It is proposed to test music intervention adapted to parabolic flights (hypergravity vs. microgravity), analog simulations or under permanent microgravity. Further studies may consider to include a wider historical musical selection for a longer time and the psycho-physiological measurements of instrumental practice. The continuation of music research in space could conduct to select music periods/styles that are specifically useful to control mood states, avoid sleep disorders, extend/improve mental and physical performance on astronauts. In long-term spaceflight music therapy could be one of the most important psycho-physiological countermeasures.

\section{ACKNOWLEDGMENT}

Special Thanks to Nigel Savage, Programme Coordinator for University Student Experiments at the ESA Education Office, to Loï , Endorsed Professor for all his support in physiology, hardware travel organization. Thanks to Timo Frett, Guido and Alexandra Noppe from DLR-facility for their flexibility to adapt the subject's recruitment and the centrifuge audio/sound hardware for this music experiment.Thanks to Tamás Nagy and the Hungarian Academy of Sciences (TTK) coordinating in advance travel/accommodation for Spanish/Hungarian team members and thanks to CNES grant for subcollaborating with the galvanic skin device and travel/accommodation for French team members. Special thanks to the European Low Gravity Research Association supporting this first endeavor with music therapy for human spaceflights.

\section{REFERENCES}

[1] Bonjour, J. (2015). de l'accélération de la gravité sur les réponses cardio-respiratoires à l'exercice chez l'homme. https://tel.archives-ouvertes.fr/tel-00690482

[2] Bonny, H. L. (1975/2002). Music and consciousness. In L. Summer (Ed.), Music and consciousness: The evolution of guided imagery and music (pp.77-92). Gilsum, NH: Barcelona Publishers.

[3] Fachner, J. C. (2019) "Telling me not to worry..." Hyperscanning and Neural Dynamics of Emotion Processing During Guided Imagery and Music. Doi: https://doi.org/10.3389/fpsyg.2019.01561

[4] Goldberg F. (1992). Images of emotion: The role of emotion in guided imagery and music. Journal of the Association for Music \& Imagery, 1,5-17

[5] J. F., \& Kompier, M. A. J. (2014). Music and psychophysiological recovery from stress. Psychosomatic Medicine, 76(7), 529537. https://doi.org/10.1097/PSY.0000000000000094

[6] Kanas, N. (2015) Humans in Space: The psychological hurdles. Springer Praxis Book. Doi: 10.1007/978-3-319-18868-3

[7] Schneider, S., Peipsi, A., Stokes, M., Knicker, A., \& Abeln, V. (2015). Feasibility of monitoring muscle health in microgravity environments using Myoton technology. Medical \& Biological Engineering \& Computing, 53(1), 57-66. https://doi.org/10.1007/s11517-014-1211-5

[8] Yang, Y., Baker, M., Graf, S., Larson, J., \& Caiozzo, V. J. (2007). Hypergravity resistance exercise: the use of artificial gravity as potential countermeasure to microgravity. Journal of Applied Physiology, 103(5), 1879-1887. 